\title{
CAPACITAÇÕES TECNOLÓGICAS DE MICRO E PEQUENAS EMPRESAS INSERIDAS EM REDES TECNOPRODUTIVAS: O CASO DA ELETROMETAL-MECÂNICA EM JOINVILLE (SC)
}

\author{
Fabio Stallivieri* ${ }^{*}$ \\ Renato Ramos Campos ${ }^{* *}$ \\ Jorge Brito ${ }^{* * * *}$
}

RESUMO Este trabalho observa as capacitações desenvolvidas por micro e pequenas empresas inseridas em redes tecnoprodutivas no arranjo produtivo eletrometalmecânico da microrregião de Joinville, localizada no nordeste do Estado de Santa Catarina. O arranjo é caracterizado por uma densa estrutura produtiva local e pela grande heterogeneidade em relação ao tamanho das empresas, criando especializações e complementaridades por tamanho de estabelecimentos, dentro das diversas atividades do complexo. A análise da divisão do trabalho no arranjo, das especializações por tamanho de empresas, combinadas com as interações de mercado e as formas de subcontratação existentes na estrutura produtiva, possibilitará compreender as características de inserção das micro e pequenas empresas e as capacitações tecnológicas desenvolvidas por essas. O objetivo deste trabalho consiste em analisar, a partir do referencial teórico neo-shumpeteriano, as distintas capacitações tecno-

* Artigo recebido em 16 de setembro de 2006 e aprovado em 28 de junho de 2007. Os autores agradecem o apoio financeiro do CNPq, da CAPES e da FAPERJ, para o desenvolvimento de suas pesquisas.

** Doutorando do Programa de Pós-graduação em Economia da Universidade Federal Fluminense, e-mail: fabio_stallivieri@yahoo.com.br

*** Professor do Departamento de Economia da Universidade Federal de Santa Catarina, e-mail: recampos@cse.ufsc.br

$\star \star \star \star$ Professor da Faculdade de Economia da Universidade Federal Fluminense, e-mail: jbrit@terra. com.br 
lógicas desenvolvidas pelas micro e pequenas empresas, derivadas das diferentes formas de inserção na estrutura produtiva local. Para tanto, realizou-se uma pesquisa de campo, na qual foram entrevistadas 83 empresas de diversos portes. Observou-se que há tipos distintos de redes tecnoprodutivas no local, consideradas as formas de governança, as características produtivas e tecnológicas e a natureza dos processos de aprendizagem. Tais especificidades afetaram com diferente intensidade as possibilidades de capacitação tecnológica das empresas, que foram influenciadas também pelas suas relações com agentes externos ao arranjo.

Palavras-chave: eletrometal-mecânica de Joinville; micro e pequenas empresas; redes de cooperação tecnoprodutivas

Código JEL: O33; L67

\title{
TECHNOLOGICAL CAPABILITIES OF SMALL AND MICRO FIRMS INSERTED IN TECHNO-PRODUCTIVE NETWORKS: THE CASE OF ELECTROMETAL-MECHANIC INDUSTRY OF JOINVILLE (SC)
}

\begin{abstract}
This paper analyses the capabilities developed by micro and small companies inserted in techno-productive networks in the eletrometal-mechanic productive arrangements of the region of Joinville, located in the northeast of the State of Santa Catarina. This arrangement is characterized by a strongly diversified and heterogeneous productive structure, with patterns of specialization and complementarities according to the size of establishments and along different activities. The analysis of the labor division in the arrangement and of the specializations by size of the companies, combined with the market interactions and the types of sub contraction, will help to comprehend how micro and small companies insert themselves in the arrangement and technological capabilities they develop. The study is based on the neo-schumpeterian theoretical framework and has as its main objective the analysis of the different technological capabilities developed by these types of firms, according to their pattern of insertion in the local productive structure. For this purpose a survey with 83 companies of different sizes was made. An important finding was the existence of several kinds of techno-productive networks, which vary according to the forms of governance, the productive and technological characteristics and the nature of the learning processes. Such specificities affect, with different intensities, the possibilities of technological capacity building, which were also influenced by the relations with agents outside the arrangement.
\end{abstract}

Key words: electrometal-mechanic industry of Joinville; small and medium enterprises - SMEs; techno-productive cooperation networks 


\section{INTRODUÇÃO}

No desenvolvimento econômico do Estado de Santa Catarina, as indústrias eletrometal-mecânicas tiveram papel de destaque no contexto de uma estrutura produtiva bastante diversificada. As atividades relacionadas a essas indústrias são responsáveis por aproximadamente $25 \%$ do valor da transformação industrial catarinense, e a microrregião de Joinville apresenta os índices mais elevados de especialização ${ }^{1}$ do Estado.

Com o amadurecimento de sua estrutura industrial, a microrregião passou a ser reconhecida nacional e internacionalmente por sua forte tradição industrial, mais especificamente em relação à eletrometal-mecânica e à indústria têxtil. Na microrregião, aproximadamente 30\% da mão-de-obra estão alocados na eletrometal-mecânica, com a presença de 835 empresas, dos mais diversos portes, atuando nessa indústria (RAIS, 2003). Essa forte participação no emprego e esse elevado número de estabelecimentos ganha ainda mais destaque considerando-se a diversificação da estrutura produtiva local, com a presença significativa de outras indústrias, como a têxtil, a alimentícia, a de materiais plásticos, entre outras.

Nessa aglomeração produtiva de empresas, desenvolveu-se simultaneamente uma estrutura institucional que inclui associações de classe, sindicatos, universidades, escolas técnicas e centros de treinamento e formação profissional. Tais organizações desenvolvem funções de coordenação, de ensino e treinamento de recursos humanos, e tecnológicas. Em uma caracterização dessa estrutura, a utilização de um recorte analítico baseado no conceito de "redes tecnoprodutivas" produtivas mostra-se particularmente útil. Essas redes podem ser caracterizadas como arranjos institucionais que possibilitam uma organização eficiente de atividades econômicas, através da coordenação de ligações sistemáticas estabelecidas entre agentes interdependentes, refletindo uma opção metodológica que privilegia o papel desempenhado por "subsistemas" estruturados na modulação da dinâmica de transformação das estruturas industriais.

Este trabalho tem como objetivo analisar as distintas características relacionadas ao esforço de capacitação, à aprendizagem, à realização de atividades cooperativas e ao desempenho inovativo, de micro e pequenas empresas (MPEs) do arranjo eletrometal-mecânico da microrregião de Joinville, a partir da inserção dessas em redes tecnoprodutivas específicas. Para tanto, além dessa breve introdução, ele é dividido em mais seis seções. A primeira 
seção apresenta uma revisão dos conceitos considerados relevantes para a análise. A segunda descreve os procedimentos metodológicos. A terceira apresenta de forma sucinta a estrutura produtiva local. Na quarta seção, descrevem-se os tipos de redes tecnoprodutivas identificadas no arranjo. $\mathrm{Na}$ quinta, realiza-se uma análise multivariada de cluster para observar as características das atividades inovativas, de cooperação e o desempenho tecnológico das empresas nas diferentes redes localizadas no arranjo. Na última seção são apresentadas as considerações finais.

\section{REFERENCIAL ANALÍtico}

A importância crescente atribuída à consolidação de práticas cooperativas e aos processos de aprendizado por interação está vinculada à visão sistêmica do processo de inovação. Nessa perspectiva, a capacidade de geração, difusão e utilização de novos conhecimentos é concebida como um processo que transcende a esfera da firma individual e passa a depender da contínua interação entre firmas e destas com outras organizações e instituições que constituem sistemas de inovação em diferentes âmbitos (Vargas, 2002). Em particular, esse modelo interativo de inovação ressalta a relevância da cooperação entre firmas e demais instituições e, portanto, o papel dos vínculos e redes envolvendo diferentes organizações.

A aglomeração territorial de empresas em torno de arranjos ou sistemas produtivos localizados facilita o engajamento desses atores em processos de aprendizado interativo. Nesse tipo de ambiente, o conhecimento tende a se tornar incorporado não somente nas qualificações individuais e nos procedimentos e rotinas das organizações, como também no próprio ambiente local ou nos vínculos de interação entre os diferentes atores e desenhos institucionais. A habilidade das empresas em criar conhecimento vai capacitálas a interagir com os demais atores locais em um processo de aprendizado coletivo, no qual conhecimentos que são em parte codificados e em parte tácitos são trocados e utilizados. Nesse aspecto, capacitações localizadas se refletem no conhecimento incorporado em indivíduos, empresas e na própria estrutura institucional presente em sistemas produtivos territoriais.

Não obstante essa percepção da importância crescente que assumem as práticas cooperativas e o aprendizado localizado no âmbito de aglomera- 
ções produtivas, verifica-se que existem ainda lacunas consideráveis na análise tanto das formas de mensuração desses processos quanto do seu impacto efetivo sobre o desempenho inovativo de empresas articuladas em torno de arranjos produtivos locais. Para avançar nessa discussão, é importante reconhecer três aspectos fundamentais relacionados à consolidação de arranjos ou sistemas produtivos localizados. O primeiro deles decorre da constatação de que esses arranjos constituem um locus de aglutinação e criação de competências, por meio de processos coletivos de aprendizado institucionalmente condicionados. Um segundo aspecto importante, que decorre naturalmente do anterior, está relacionado ao pressuposto de que o mapeamento e a avaliação das práticas cooperativas são fundamentais para a compreensão das características dos processos de aprendizado em arranjos e sistemas produtivos. Por fim, um terceiro aspecto envolve articulação existente entre consolidação de práticas cooperativas, aprofundamento do aprendizado por interação e fortalecimento da competitividade e capacitação dos agentes.

Adicionalmente, é importante considerar que os arranjos e sistemas produtivos não devem ser concebidos como estruturas monolíticas, nas quais as forças que comandam uma determinada "dinâmica interna" apontam necessariamente para uma "convergência" ou "equalização" das estratégias e dos níveis de capacitação dos agentes em seu interior. Pelo contrário, as evidências sugerem que esses arranjos são estruturas intrinsecamente complexas e heterogêneas, cujos agentes possuem características assimétricas, vinculadas à consolidação de competências técnicas e cognitivas específicas, que condicionam as possibilidades de interação mútua entre eles. ${ }^{2}$ Esses agentes articulam-se através de redes de relacionamentos que conformam uma determinada divisão de trabalho - ou determinada "estrutura de governança", em uma concepção mais institucionalista - interna a cada arranjo. Em função das características desse sistema de divisão de trabalho, definem-se um determinado grau de interdependência técnica e uma logística interna ao arranjo, vinculada à presença de diversos tipos de sinergias entre as diversas atividades realizadas.

Para uma melhor compreensão da "estrutura de governança" subjacente a esses arranjos, é útil supor que essa estrutura pode ser mais bem captada a partir de um detalhamento de determinadas redes tecnoprodutivas, através 
das quais se conformam as articulações e interações entre agentes no interior daqueles arranjos. No plano metodológico, a ênfase na análise dessas redes está presente em abordagens que privilegiam um recorte "mesoeconômico" da dinâmica industrial, as quais ressaltam o papel desempenhado por "subsistemas" estruturados na modulação dessa dinâmica (Bandt, 1989). Esses "subsistemas" podem apresentar uma grande diversidade institucional, operando como "linhas de força” básicas do processo de transformação das estruturas industriais. Em especial, eles caracterizam-se pela presença de uma diversidade de atores que desempenham funções heterogêneas. Outra característica importante de tais subsistemas é a existência de uma autonomia relativa em relação às forças externas, bem como a presença de um certo grau de "auto-organização" e de uma capacidade de transformação que confere a essas estruturas um caráter essencialmente dinâmico. Nessa perspectiva, as redes de firmas podem ser concebidas como um subconjunto organizado de atores interdependentes, estando associadas à organização simultânea de relações de concorrência e cooperação entre seus membros, decorrente da necessidade de compatibilizar-se a exploração de complementaridades de competências com a barganha pela apropriação dos ganhos econômicos gerados.

A cooperação interindustrial que caracteriza as redes tecnoprodutivas possibilita a aglutinação de múltiplas competências, impulsionando o potencial inovativo dos agentes a elas integrados. A montagem dessas redes é uma alternativa eficaz para a adequação das "configurações organizacionais" a um ambiente mutável e com informações fragmentadas. Depois de configuradas, as redes podem mudar o próprio ambiente no qual se inserem, favorecendo um enfrentamento coordenado de turbulências ambientais, através de um processo de elaboração de convergências, do tratamento coletivo de informações e de busca de soluções, e da consolidação de um locus de acumulação de recursos coletivos específicos. Considerando o aprendizado como um processo interativo, essas formas organizacionais podem afetar a capacitação e o desempenho das firmas. Nesse sentido, Teece (1989) comprovou a existência de custos significativos associados à transmissão e absorção de conhecimentos técnicos não incorporados a equipamentos. Esse fenômeno deriva do caráter tático, presente na grande maioria das capacitações tecnológicas e organizacionais. A transmissão destas exige 
um aprendizado que costuma ser decorrente de uma interação direta e sistemática entre o transmissor e o receptor das informações.

Malerba (1992) aponta que a raiz da mudança técnica incremental está associada a múltiplas formas de aprendizado, as quais se vinculam a fontes internas ou externas às firmas. O learning by doing requer conhecimentos internos e está relacionado à atividade produtiva. O learning by using requer conhecimentos internos e externos e relaciona-se ao uso de produtos, insumos, máquinas, resultando em melhoramentos no produto e nos processos. $\mathrm{O}$ learning from advances em $S \& T$ é externo à firma e relaciona-se a avanços em C\&T. O learning fron inter-industry spillovers é externo à firma e relaciona-se à interação com fontes de conhecimento, tais como clientes, fornecedores de bens de capital e com outras firmas. O learnig by searching é interno à firma e relaciona-se a atividades formais que geram novos conhecimentos. É a partir do manejo, integração e operacionalização dessas múltiplas formas de aprendizado que se consolidam competências empresariais fundamentais para um melhor desempenho competitivo. Ressalta-se aqui a crescente importância das políticas públicas e do arcabouço institucional, no suporte de $\mathrm{P} \& \mathrm{D}$, na difusão de tecnologias e na criação de estímulos a múltiplas formas de cooperação.

Considerando que a dinâmica econômica atual está cada vez mais associada ao aprendizado interativo e aos processos de inovação, as configurações organizacionais em rede se tornariam particularmente importantes, tornando possível, através do estabelecimento de laços sistemáticos entre as firmas, elevar a capacidade de inovação para um mesmo montante de P\&D despedido internamente, em função da compatibilização dos padrões cognitivos e dos procedimentos de busca entre diversos agentes com competências complementares. Diversos tipos de efeito spillover tendem a ser reforçados nessas estruturas, devido à existência de canais sistemáticos de integração entre os agentes. Além disso, o intercâmbio sistemático de informações entre os agentes favorece uma maior coordenação das estratégias técnicas implementadas, assim como o acesso a conhecimentos externos à indústria também é facilitado pelas configurações em rede. Finalmente, as redes elevam o impacto positivo de novos conhecimentos em termos de performance tecnológica e dos processos produtivos (Britto, 1999).

Partindo da suposição de que as redes tecnoprodutivas são instâncias fundamentais para a integração de competências e o aprofundamento do 
aprendizado, é possível associar à conformação morfológica dessas redes alguns elementos básicos constituintes, cuja combinação delimita as possibilidades de evolução ao longo de uma trajetória virtuosa de incremento de capacitações e reforço da competitividade. Com esse intuito, é possível considerar os agentes, as ligações estabelecidas entre eles e os fluxos gerados a partir dessas ligações como elementos básicos constituintes dessas redes, os quais assumem características específicas em cada situação particular. No tocante aos agentes, estes apresentam características e competências específicas, a partir das quais procuram coordenar, com vistas a determinados objetivos, suas atividades produtivas e tecnológicas. Por outro lado, essas redes estão também baseadas em uma estrutura de ligações entre agentes e atividades que conformam uma determinada divisão de trabalho interna à rede, a qual reforça a sua coesão e adaptabilidade ao longo do tempo.

Já no que se refere à caracterização dos fluxos internos a essas redes, dois recortes analíticos são possíveis. O primeiro deles procura distinguir fluxos tangíveis e intangíveis. Os fluxos tangíveis estão baseados em transações recorrentes estabelecidas entre os agentes, através das quais são transferidos insumos e produtos. Nesse caso, o processo de emissão e recepção de estímulos compreende operações de compra e venda realizadas entre os agentes integrados à rede. Simultaneamente aos fluxos tangíveis, é possível caracterizar outros fluxos internos que assumem um caráter menos tangível. Em particular, é possível destacar determinados "fluxos informacionais" que conectam os diversos agentes integrados às redes. Uma parcela importante das informações transmitidas é de caráter "tácito", estando baseada em padrões cognitivos idiossincráticos retidos pelos agentes responsáveis pela transmissão e recepção das mesmas. Assim, em arranjos associados a atividades tradicionais, é mais provável que os fluxos mais relevantes sejam aqueles de natureza tangível, envolvendo, por exemplo, uma sofisticação dos procedimentos de subcontratação, enquanto em outras circunstâncias, associadas a atividades de maior conteúdo tecnológico, os fluxos intangíveis de maior conteúdo informacional costumam ser mais relevantes.

O conceito de "redes de firmas" tem sido utilizado tanto por análises estritamente qualitativo-descritivas baseadas em "estudos de caso" quanto por análises de cunho mais quantitativo, que procuram definir critérios específicos para identificação e caracterização desses arranjos. Nas análises de 
cunho qualitativo, o que se procura, em geral, é detalhar a conformação institucional dessas estruturas, utilizando-se critérios específicos de agregação e classificação dos agentes, baseados em atributos que lhes são intrínsecos ou na posição por eles ocupadas em um determinado esquema de divisão de trabalho. Adicionalmente, algumas análises de cunho "qualitativo" procuram avançar no sentido de uma classificação tipológica dessas redes, geralmente baseada em fatores subjacentes à sua estrutura interna ou no tipo de ganho proporcionado para as empresas participantes. Dentre as análises quantitativas, é possível destacar aquelas que permitem o agrupamento de pontos (ou "nódulos") que estabelecem interações sistemáticas entre si, através da definição de variáveis que expressam essas interações, da quantificação das mesmas e da realização de simulações que conduzem à formação de clusters de pontos com propriedades comuns. É também comum a realização de uma "análise de correspondência” visando a possibilitar a localização dos grupos de agentes em um quadro de contingência (geralmente bidimensional), construído a partir de associações entre variáveis. Adicionalmente, algumas análises complementam esse enfoque quantitativo com uma análise qualitativa dos diversos grupos identificados e de possíveis inter-relações entre os mesmos.

Buscando integrar as dimensões qualitativa e quantitativa da análise, é possível avançar na direção da realização de um esforço de sistematização de informações coletadas em estudos empíricos, visando a captar as principais características e a importância relativa de determinadas "dimensões" do processo de cooperação e aprendizado nas situações retratadas. Em particular, é possível associar um conjunto específico de questões, bem como os indicadores correspondentes, de modo a contemplar três dimensões interrelacionadas. A primeira delas refere-se à caracterização da estrutura interna das redes tecnoprodutivas, em termos de seus principais agentes, de suas respectivas competências e dos padrões de relacionamentos estabelecidos entre eles, responsáveis pela consolidação de uma forma particular de governança. A segunda dimensão refere-se à caracterização da dinâmica interna (ou das formas de operação) características dessas redes, associadas às forças endógenas que condicionam a sua evolução e transformação ao longo do tempo. Na caracterização dessa dinâmica, particular importância deve ser atribuída à discussão das particularidades dos fluxos tangíveis e intangí- 
veis internos ao arranjo e aos reflexos dos mesmos em termos dos processos de aprendizado. Finalmente, uma terceira dimensão relevante refere-se à avaliação do desempenho inovativo e competitivo das redes tecnoprodutivas ao longo do tempo.

\section{PROCEDIMENTOS METODOLÓGICOS}

Na microrregião de Joinville, aproximadamente 30\% da mão-de-obra estão alocados no setor eletrometal-mecânico, com a participação de uma ampla gama de empresas dos mais diversos portes. O arranjo eletrometal-mecânico possui uma densa estrutura produtiva local e grande heterogeneidade no tamanho das empresas, observando-se especializações por tamanho de empresas dentro dos diversos grupos de atividades. As características da estrutura produtiva local relacionadas ao porte e atividades dos estabelecimentos são apresentadas na tabela 1 .

Os dados para este trabalho foram obtidos em pesquisa de campo, na qual foram entrevistadas 83 empresas, sendo 37 micro, 34 pequenas, 8 médias e 4 grandes empresas, atuando em atividades relacionadas às indústrias eletrometal-mecânicas e localizadas nos Municípios de Joinville e Jaraguá do Sul. A análise das informações coletadas junto a empresas do arranjo eletrometal-mecânico aponta no sentido de uma intrincada estrutura de relacionamentos internos, a qual constitui evidência da complexa dinâmica interna de operação desse arranjo, no tocante à criação de estímulos ao

aprofundamento de mecanismos interativos de aprendizado capazes de reforçar a capacitação dos agentes locais. Há também indícios de que diferentes formas de ações cooperativas estão presentes no arranjo, particularmente envolvendo relacionamentos verticais entre clientes e fornecedores integrados a redes de subcontratação.

Com as informações obtidas por meio do questionário utilizado nas entrevistas, ${ }^{3}$ foram elaborados os seguintes indicadores: ${ }^{4}$

Indicadores de esforço tecnológico: (a) Forma e freqüência das atividades de inovação realizadas pelas empresas (YE1); (b) Esforço de treinamento e capacitação de recursos humanos realizados pela empresa (YE2).

Indicadores de aprendizagem tecnológica: (a) Importância atribuída pelas empresas aos processos de aprendizagem interna à firma (YA1); (b) Grau 


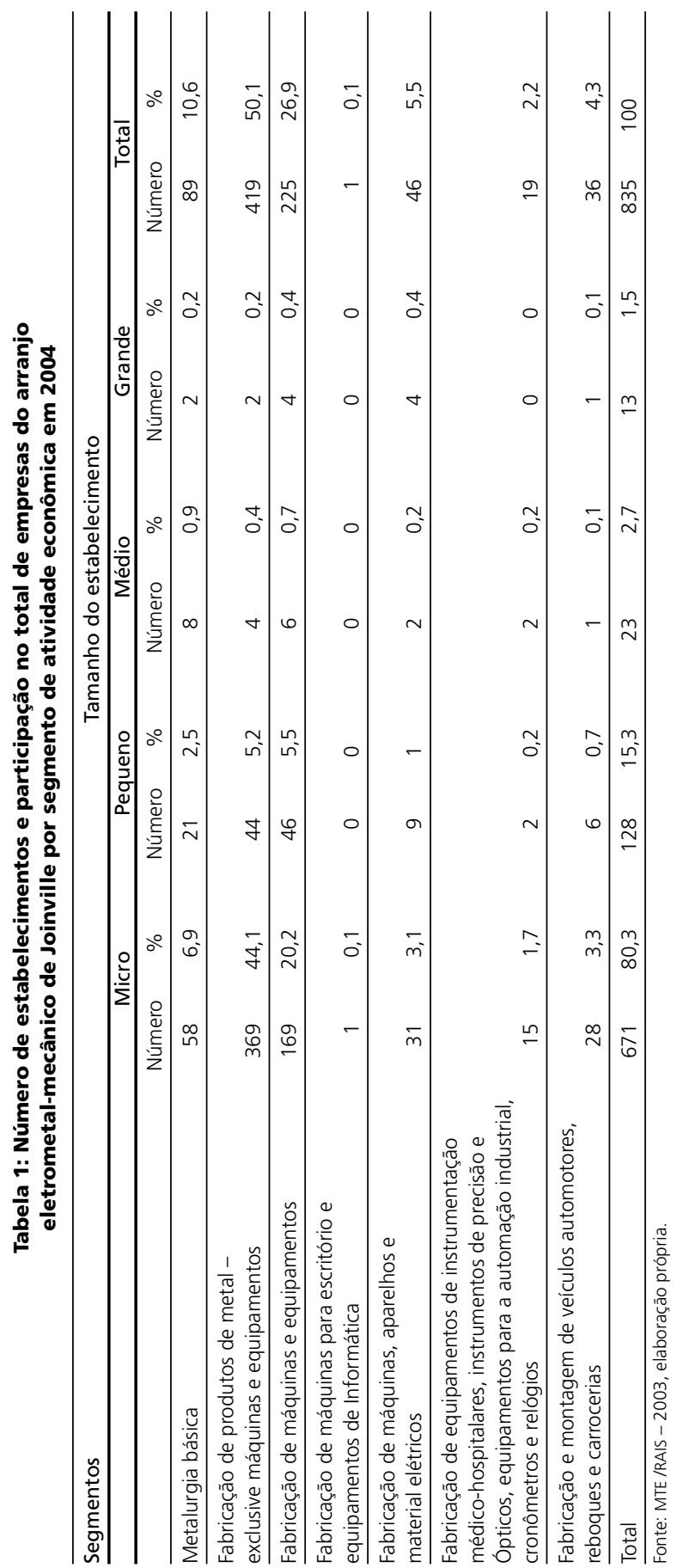


de formalização da aprendizagem interna à firma (YA2); (c) Importância atribuída pelas empresas à aprendizagem por interação com outros agentes produtivos (YA3); (c) Grau de formalização do aprendizado por interação com outros agentes produtivos (YA4); (c) Importância atribuída pelas empresas à aprendizagem por interação com agentes de ciência e tecnologia (YA5); (d) Grau de formalização da aprendizagem por interação com agentes de ciência e tecnologia (YA6); (e) Importância atribuída pelas empresas à aprendizagem por outras fontes de informação (YA7); (f) Grau de formalização do aprendizado por outras fontes (YA8).

Indicadores da ação cooperativa das empresas: (a) Importância atribuída pelas empresas à cooperação com agentes produtivos (YC1); (b) Grau de formalização da cooperação com agentes produtivos (YC2); (c) Importância atribuída pelas empresas à cooperação com agentes de ciência e tecnologia (YC3); (d) Grau de formalização da cooperação com agentes de ciência e tecnologia (YC4); (e) Importância atribuída pelas empresas à cooperação com outros agentes (YC5); (f) Grau de formalização da cooperação com demais agentes (YC6).

Indicadores de desempenho das empresas: (a) Introdução de inovações pelas empresas (YD1); (b) Importância atribuída pelas empresas ao resultado da atividade inovativa (YD2); (c) Importância atribuída pelas empresas aos resultados da cooperação (YD3); (d) Importância atribuída pelas empresas aos resultados das atividades de treinamento (YD4).

Utilizou-se a "análise multivariada de cluster" ${ }^{5}$ para identificar as características dos processos de aprendizagem por fontes internas e externas às empresas, as formas de cooperação das empresas no arranjo produtivo e o desempenho das empresas segundo sua inserção nas diferentes redes tecnoprodutivas existentes no arranjo. A identificação dos tipos de redes existentes no local leva em consideração três atributos dessas estruturas: o grau de interdependência entre os agentes, dado pelo tipo de atividade exercida na estrutura produtiva; a forma de coordenação/governança da estrutura, como apresentado em vários trabalhos (Britto, 1999; Suzigan, Garcia \& Furtado, 2003; Storper \& Harrison, 1991; entre outros); e a periodicidade dos relacionamentos, no sentido de que a participação em uma rede requer que o relacionamento entre as empresas seja periódico, no mínimo semestral. 
Foram identificados três tipos de redes de firmas com base nas relações tecnoprodutivas, duas coordenadas por grandes e médias empresas locais e uma relacionada a redes de MPEs. $\mathrm{O}$ primeiro tipo corresponde às redes de subcontratação para o fornecimento de materiais $\operatorname{diretos}^{6}$ (Rede Tipo 1) às grandes e médias empresas (incluem-se aqui as empresas envolvidas com subcontratação de atividades, como fornecimento de insumos e componentes e desenvolvimento de produto). $\mathrm{O}$ segundo tipo corresponde às redes para o fornecimento de materiais indiretos ${ }^{7}$ e prestação de serviços industriais (Rede Tipo 2) para as grandes e médias empresas (consideram-se as subcontratações de etapas do processo produtivo e dos serviços produtivos especializados). O terceiro tipo de rede é formado por MPEs que são subcontratantes de outras micros e pequenas (Rede Tipo 3), para diversas atividades, como, por exemplo, prestação de serviços e fornecimento de peças e componentes.

\section{A ESTRUTURA PRODUTIVA do ARRANJO}

\section{ELETROMETAL-MECÂNICO DA MICRORREGIÃO DE JOINVILLE}

No arranjo produtivo eletrometal-mecânico da microrregião de Joinville, são produzidos uma ampla gama de bens relacionados a essa indústria. No local ocorre a produção de bens intermediários, bens de capital e bens de consumo duráveis. Essa elevada variedade de bens produzidos, por um lado, estabelece distintas possibilidades de relações na cadeia produtiva; por outro, leva as empresas a desenvolverem diversos níveis de especialização, possibilitando em nível local uma forte divisão do trabalho. Ainda cabe destacar que, independente do tipo de bem produzido, as empresas dessas indústrias demandam uma série de serviços relacionados principalmente aos processos produtivos. Além da manutenção de máquinas e equipamentos, existe uma infinidade de materiais indiretos ${ }^{8}$ que são demandados de forma homogênea por todas as empresas.

O quadro 1 procura resumir algumas das características dos bens produzidos no arranjo, apresentando as relações na cadeia produtiva, as possibilidades de divisão do trabalho e o grau de modularidade dos mesmos. Constata-se que, de forma geral, os bens produzidos no arranjo possibilitam a consolidação de complexas relações na cadeia produtiva, tanto a montante 
quanto a jusante. Desse modo, são também elevadas as possibilidades de divisão do trabalho para a produção desses bens. O grau de modularidade dos bens é bastante diversificado, fazendo as empresas operarem com distintos níveis de especialização.

Constata-se, portanto, que o arranjo investigado apresenta elevadas possibilidades de divisão do trabalho, uma vez que está presente a grande maioria das atividades das indústrias eletrometal-mecânicas, com um grande número de empresas e elevada heterogeneidade no porte das mesmas. Essa densidade, por um lado, resulta das externalidades que há mais de um século desenvolvem-se no arranjo, criando demandas locais que estimulam complementaridades e a expansão simultânea no local dos vários segmentos dessas indústrias. Por outro lado, os processos mais recentes de reestruturação produtiva das grandes e médias empresas, que terceirizaram etapas de seus processos produtivos, estimularam o desenvolvimento de grande número de MPEs. Logo, essa densa estrutura produtiva cria intensas relações dentro do território, que é um importante mercado para muitas empresas. Nesse contexto, a investigação dos impactos dessas inter-relações locais sobre a estrutura, a capacitação e o desempenho inovativo do arranjo torna-se um tema particularmente relevante.

Quadro 1: Tipos de bens produzidos e característica dos produtos gerados

\begin{tabular}{|c|c|c|c|c|c|}
\hline \multirow{3}{*}{$\begin{array}{l}\text { Tipo de bem } \\
\text { produzido }\end{array}$} & \multirow{3}{*}{$\begin{array}{l}\text { Produtos } \\
\text { Peças fundidas }\end{array}$} & \multirow{3}{*}{$\begin{array}{c}\begin{array}{c}\text { Modularidade } \\
\text { do produto }\end{array} \\
\text { Baixa }\end{array}$} & \multicolumn{2}{|c|}{$\begin{array}{l}\text { Relações na } \\
\text { cadeia produtiva } \\
\text { Jusante / Montante }\end{array}$} & \multirow{3}{*}{$\begin{array}{c}\begin{array}{c}\text { Possibilidades } \\
\text { de divisão } \\
\text { do trabalho }\end{array} \\
\text { Baixas }\end{array}$} \\
\hline & & & Baixas & Elevadas & \\
\hline & & & & & \\
\hline & $\begin{array}{l}\text { Motores elétricos } \\
\text { e componentes etc. }\end{array}$ & Elevada & Elevadas & Elevadas & Elevadas \\
\hline $\begin{array}{l}\text { Bens de } \\
\text { consumo } \\
\text { duráveis }\end{array}$ & $\begin{array}{l}\text { Eletrodomésticos, } \\
\text { equipamentos de } \\
\text { ginástica, equipamentos } \\
\text { de jardinagem, ônibus e } \\
\text { carrocerias etc. }\end{array}$ & Elevada & Elevadas & Baixas & Elevadas \\
\hline $\begin{array}{l}\text { Bens } \\
\text { de capital }\end{array}$ & $\begin{array}{l}\text { Compressores, máquinas } \\
\text { e ferramentas, máquinas } \\
\text { e equipamentos para } \\
\text { indústrias diversas e } \\
\text { específicas etc. }\end{array}$ & Elevada & Elevadas & Elevadas & Elevadas \\
\hline Materiais indiretos & $\begin{array}{l}\text { Moldes, ferramentas, } \\
\text { matrizes etc. }\end{array}$ & Baixa & Baixas & Elevadas & Baixas \\
\hline
\end{tabular}

Elaboração própria. 


\section{CARACTERÍSTICAS DAS REDES DE FIRMAS E A NATUREZA DA INSERÇÃO DAS MPES}

Nas redes de fornecimento de materiais diretos (Rede Tipo 1), foram identificadas 17 empresas da amostra, empregando em média 32 funcionários, com um faturamento médio anual em 2002 de R $\$ 1.781 .800,00 .^{9}$ As MPEs inseridas nessas estruturas atuam como fornecedoras, integrando redes verticais coordenadas por uma empresa que exerce considerável influência sobre as ações dos agentes de menor porte que integram a cadeia produtiva. Os requisitos exigidos às micro e pequenas empresas para participarem dessas redes dependem das estratégias de subcontratação específicas de cada grande e média empresa. ${ }^{10}$

Verifica-se, em alguns casos, um criterioso processo de seleção dos fornecedores ${ }^{11}$ desenvolvido pelas empresas de maior porte, que consiste em identificar, desenvolver, negociar, certificar e monitorar o fornecedor, evitando situações de não-conformidades e dispensando a realização do controle de qualidade nos componentes fornecidos. Nesses casos, os fornecedores estão sujeitos a auditorias ${ }^{12}$ e recebem periodicamente relatórios em relação às não-conformidades detectadas. Em outros casos, ${ }^{13}$ o processo de seleção dos fornecedores é menos rigoroso, ocorrendo o teste de qualidade ${ }^{14}$ dos componentes na empresa contratante.

Os contatos regulares para pedidos são estabelecidos com os fornecedores via e-mail, telefone, fax e, em alguns casos, pelo kanbam. Já os contatos para o fornecimento de um novo item ou para melhorias nos componentes fornecidos são feitos através dos departamentos, envolvendo recursos humanos específicos relacionados ao controle de qualidade ou ao desenvolvimento de produtos. Em todos os casos há a troca regular de relatórios, com o intuito de se ter acesso às formas de controle de qualidade dos produtos fornecidos e de melhorar as relações internas da rede.

As MPEs inseridas nessas redes também precisam atender às exigências ligadas à logística das empresas contratantes. Dependendo do tipo de componente fornecido e do grau de importância dos mesmos, observa-se até mais de um fornecimento diário, ${ }^{15}$ sendo as peças entregues diretamente na linha de produção, e utilizando-se o just in time. Cabe salientar que esses processos não se aplicam às commodities, como, por exemplo, aços laminados, fios e cabos. ${ }^{16}$ 
Os contratos, nesses casos, são mais de longo prazo e com especificidades, início, meio e fim, sendo as mudanças no ambiente econômico que levem a alterações nos montantes contratados comunicadas com antecedência, e a maioria dos pedidos é feita em aberto. ${ }^{17}$ Normalmente, os conflitos são resolvidos por negociação entre as duas partes. ${ }^{18}$ Mudanças nos preços contratados são efetuadas levando em conta as planilhas de custos, ou seja, as grandes e médias empresas contratantes têm acesso à planilha de custos das MPEs contratadas e, com base nelas, são estipulados os $\operatorname{preços}^{19} \mathrm{e}$ as alterações.

As vantagens da inserção de MPEs nesse tipo de rede consistem na demanda assegurada por um certo período e nas melhorias implementadas para adequação aos requisitos exigidos. Além dessas duas vantagens, podese constatar uma terceira, mais difícil de ser quantificada, referente à abertura de novas possibilidades de negócios. Por serem fornecedoras de uma grande empresa local e atender aos requisitos de fornecimento destas, essas empresas de menor porte possuem maiores possibilidades de passarem a fornecer para outras grandes empresas, localizadas até mesmo fora do arranjo, uma vez que os requisitos exigidos, apesar de não serem homogêneos, são muito similares, isto é, constatam-se ganhos de imagem por atuarem como fornecedoras dessas empresas. Como forma de incentivo para o enquadramento às exigências, algumas grandes empresas elaboraram um sistema de premiação dos melhores fornecedores.

Em relação às MPEs inseridas em redes de fornecimento de materiais indiretos e prestação de serviços industriais (Rede Tipo 2), foram identificadas 34 empresas, com uma média de 22 funcionários cada e um faturamento médio em 2002 de $\mathrm{R} \$ 960.000,00$. Essas micro e pequenas empresas também integram redes verticais coordenadas por grandes e médias empresas locais.

O processo de seleção desses fornecedores e prestadores de serviços é significativamente distinto entre os subcontratantes. Em alguns casos, em que o material fornecido possui uma importância estratégica, as empresas também se submetem aos processos de seleção e qualificação dos fornecedores e os contatos são mais periódicos, ocorrendo o deslocamento de recursos humanos da empresa subcontratante para a empresa subcontratada, a fim de realização de testes/ensaios e para a verificação da qualidade e confiabilidade do material fornecido. ${ }^{20}$ Em outros casos, os contatos são reduzidos referentes apenas à transmissão das especificidades dos produtos/pro- 
cessos contratados, bem como a seleção é feita via mercado. ${ }^{21}$ No caso das MPEs subcontratadas para a execução de etapas do processo produtivo, a relação desenvolvida é mais periódica, ${ }^{22}$ envolvendo uma maior troca de informações e uma articulação mais estreita.

Os contratos nesse tipo de rede são de curto prazo ou inexistentes, predominando apenas pedidos específicos. As principais capacidades exigidas das empresas contratadas são a habilidade para processar conhecimentos não codificados, que resulta de ampla experiência adquirida na prática dos processos produtivos, criando nas empresas um know-how específico, e o cumprimento dos prazos de entrega. A proximidade geográfica com as empresas subcontratantes é de grande importância, já que geralmente esses serviços são contratados com uma certa urgência.

No local é grande a oferta destes serviços por empresas com níveis semelhantes de capacitações; logo, de forma geral, ${ }^{23}$ este tipo de subcontratação é feito via mercado, sendo o preço e o prazo de entrega os requisitos mais importantes. O principal incentivo para a participação nesse tipo de rede é a demanda assegurada por um período específico. Nessa rede, também não há exigências de exclusividade no fornecimento.

A Rede Tipo 3 é formada por micro e pequenas empresas que subcontratam outras MPEs, tendo sido identificadas 24 empresas, com um faturamento médio em 2002 de R\$4.150.000,00 e com um tamanho médio de 33 empregados. Nessa rede, as micro e pequenas empresas estão inseridas em estruturas horizontais e verticais formadas e coordenadas por MPEs. Nas redes de MPEs verticais, levando em consideração a divisão do trabalho, as especializações e complementaridades desenvolvidas palas empresas, ocorre a articulação entre elas para a produção de um determinado bem. O exemplo típico dessas estruturas são as redes formadas pelas empresas produtoras de máquinas e equipamentos, em que a empresa produtora subcontrata outras MPEs para o fornecimento de componentes e para a prestação de serviços especializados. Essa empresa subcontratante exerce a coordenação das atividades, os contratos assumem um caráter específico e há forte troca de informações entre as empresas participantes.

As redes de MPEs horizontais são formadas por empresas que produzem um mesmo bem ou serviço, que se organizam para a realização conjunta de uma atividade. Um exemplo desse tipo de configuração seriam os consórcios de exportação, tendo sido identificado no arranjo um grupo de cinco ferramentarias que formaram um consórcio de exportação de moldes e 
ferramentas. Um outro exemplo é a subcontratação de micro e pequenas empresas com a finalidade de atender a um pedido de volume elevado. ${ }^{24}$ Neste caso, a coordenação das atividades é exercida tanto pelas MPEs subcontratantes, como por agentes externos à atividade produtiva. ${ }^{25}$ Os contratos são específicos e de curto prazo e há uma forte troca de informações entre as empresas.

Portanto, verifica-se que as micro e pequenas empresas do arranjo participam de diferentes tipos de redes, ${ }^{26}$ com características específicas. O quadro 2 procura resumir algumas características de cada tipo de rede.

\section{Quadro 2: Características das redes de cooperação tecnoprodutivas} do arranjo eletrometal-mecânico da microrregião de Joinville (SC)

\begin{tabular}{|c|c|c|c|}
\hline Características & Rede Tipo 1 & Rede Tipo 2 & Rede Tipo 3 \\
\hline $\begin{array}{l}\text { Tipo de } \\
\text { transação }\end{array}$ & $\begin{array}{l}\text { Fornecimento de peças } \\
\text { e componentes }\end{array}$ & $\begin{array}{l}\text { Fornecimento de materiais } \\
\text { indiretos. Prestação de } \\
\text { serviços industriais. } \\
\text { Etapas do processo } \\
\text { produtivo }\end{array}$ & $\begin{array}{l}\text { Etapas dos processos } \\
\text { produtivos. } \\
\text { Fornecimento de peças } \\
\text { e componentes. } \\
\text { Produção de parte } \\
\text { dos lotes }\end{array}$ \\
\hline $\begin{array}{l}\text { Importância da } \\
\text { proximidade } \\
\text { geográfica }\end{array}$ & Baixa & Alta & Alta \\
\hline $\begin{array}{l}\text { Relações com o } \\
\text { mercado externo } \\
\text { ao arranjo }\end{array}$ & Elevadas & Baixas & Baixas \\
\hline $\begin{array}{l}\text { Circulação } \\
\text { de informações }\end{array}$ & Intensa & Média & Intensa \\
\hline $\begin{array}{l}\text { Complementaridade } \\
\text { e especializações } \\
\text { dos agentes }\end{array}$ & Alta & Média & Alta \\
\hline $\begin{array}{l}\text { Capacitações } \\
\text { exigidas }\end{array}$ & $\begin{array}{l}\text { Produzir com os requisitos } \\
\text { de qualidade exigidos }\end{array}$ & Know-how & $\begin{array}{l}\text { Know-how e capacidade } \\
\text { de integrar competências }\end{array}$ \\
\hline $\begin{array}{l}\text { Grau de hierarquia/ } \\
\text { coordenação }\end{array}$ & Alto/exercido pelas GMEs & Alto/exercido pelas GMEs & $\begin{array}{l}\text { Baixo/exercido por agentes } \\
\text { externos à rede ou por } \\
\text { uma MPE }\end{array}$ \\
\hline $\begin{array}{l}\text { Características } \\
\text { dos contratos }\end{array}$ & Formais e de longo prazo & $\begin{array}{l}\text { Formais e informais } \\
\text { de curto prazo }\end{array}$ & $\begin{array}{l}\text { Tanto formais quanto } \\
\text { informais com prazos } \\
\text { variados }\end{array}$ \\
\hline $\begin{array}{l}\text { Exigências de } \\
\text { exclusividade } \\
\text { no fornecimento/ } \\
\text { prestação de serviços }\end{array}$ & Baixas & Baixas & Nulas \\
\hline $\begin{array}{l}\text { Influência do } \\
\text { arcabouço } \\
\text { institucional }\end{array}$ & Nula & Nula & Alta \\
\hline
\end{tabular}

Fonte: Pesquisa de campo, 2003. 


\section{APLICAÇÃO DA TÉCNICA DE ANÁlise MULTIVARIADA DE CLUSTER PARA UMA COMPARAÇÃO ENTRE OS DISTINTOS TIPOS DE REDE}

Esta seção procura analisar, em cada uma das redes descritas, as características dos esforços inovativos, os processos de aprendizagem e de cooperação, e os indicadores de desempenho das empresas quanto à inovação.

A tabela 2 apresenta os indicadores de esforço tecnológico em cada tipo de rede. Em relação ao esforço de desenvolvimento de atividades inovativas, a Rede Tipo 3 apresenta os maiores indicadores, ou seja, o esforço de desenvolvimento dessas atividades, nesse tipo de rede, é mais elevado comparativamente às outras redes. Já o indicador relacionado ao esforço de capacitação de recursos humanos é consideravelmente mais elevado na Rede Tipo 1, demonstrando que as empresas inseridas nesse tipo de rede desenvolvem com maior intensidade atividades relacionadas a treinamento e capacitação.

A figura 1 apresenta a porcentagem de empresas de cada rede que desenvolveram as atividades inovativas de forma rotineira. Nesse sentido, a Rede Tipo 3 destaca-se pelo desenvolvimento de atividades relacionadas a pesquisa e desenvolvimento interno e pela execução de programas de treinamento orientados à introdução de inovações. Já a Rede Tipo 1 concentra seus esforços inovativos na aquisição de máquinas e equipamentos, de outras tecnologias, como softwares, e na execução de programas relacionados à gestão da qualidade. A Rede Tipo 2 desenvolve com baixa intensidade atividades relacionadas ao desenvolvimento de inovações. Percebe-se que o tipo

Tabela 2: Análise de cluster das redes segundo os indicadores de esforço, valores médios de cada cluster nos indicadores

\begin{tabular}{lcccccccc}
\hline $\begin{array}{l}\text { Indicadores } \\
\text { de } \\
\text { esforço }\end{array}$ & Rede 1-17 & Empresas & Rede 2-34 & Empresas & Rede 3-24 & Empresas & Amostra-71 & Empresas \\
\cline { 2 - 8 } & Média & $\begin{array}{c}\text { Desvio } \\
\text { padrão }\end{array}$ & Média & $\begin{array}{c}\text { Desvio } \\
\text { padrão }\end{array}$ & Média & $\begin{array}{l}\text { Desvio } \\
\text { padrão }\end{array}$ & Média & $\begin{array}{l}\text { Desvio } \\
\text { padrão }\end{array}$ \\
\hline $\begin{array}{l}\text { YD1 - } \\
\text { desenvolvimiento } \\
\text { de atividades } \\
\text { inovativas }\end{array}$ & 0,3529 & 0,2733 & 0,3272 & 0,2399 & 0,3620 & 0,2141 & 0,3266 & 0,2291 \\
\hline $\begin{array}{l}\text { YD1 - } \\
\text { treinamento e } \\
\text { capacitação } \\
\text { de recursos } \\
\text { humanos }\end{array}$ & 0,3170 & 0,2421 & 0,2935 & 0,1907 & 0,2861 & 0,2084 & 0,2740 & 0,1957 \\
\hline
\end{tabular}


Figura 1: Porcentagem de empresas e atividades inovativas desenvolvidas rotineiramente

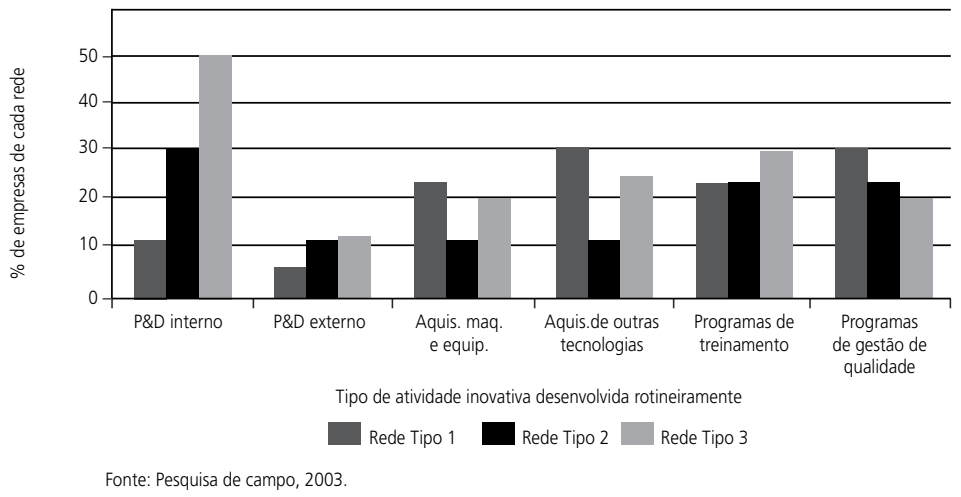

Figura 2: Porcentagem de empresas e atividades inovativas desenvolvidas rotineiramente

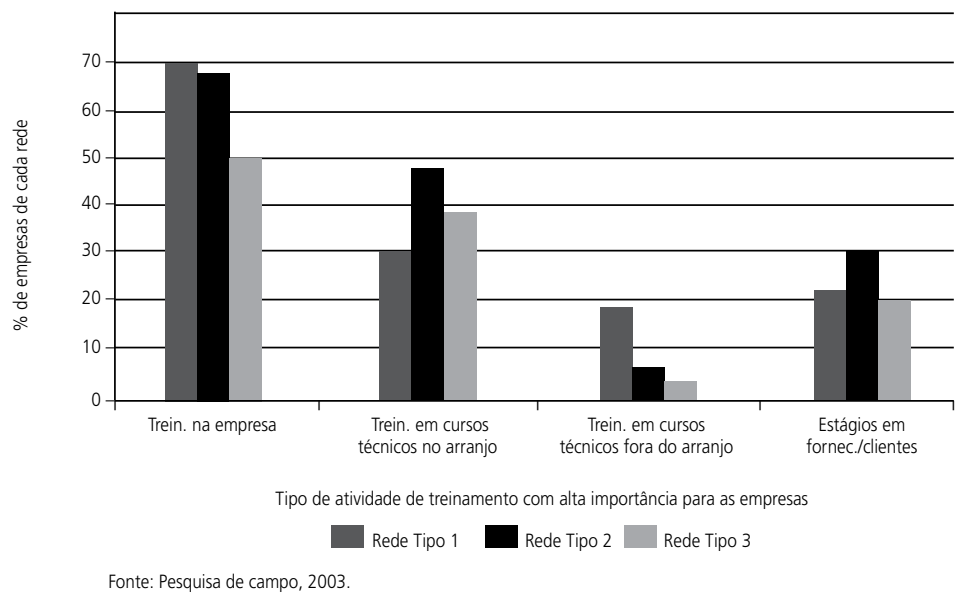

de atividade inovativa desenvolvida em cada rede está relacionado ao tipo de bem produzido. Na Rede Tipo 3, por exemplo, na qual o principal produto são bens de capital, as atividades de pesquisa são mais relevantes. $\mathrm{Na}$ Rede Tipo 1, caracterizada pelo fornecimento de peças e componentes, atividades relacionadas à qualidade e à aquisição de máquinas e equipamentos que modernizem os processos ganham maior destaque.

A figura 2 relaciona a porcentagem de empresas de cada rede que atribuem elevada importância às atividades de treinamento e capacitação de recursos humanos. Na Rede Tipo 1, destacam-se atividades de treinamento 
realizadas nas próprias empresas ${ }^{27}$ e em cursos técnicos realizados fora da microrregião. Na Rede Tipo 2, ressaltam-se o treinamento em cursos técnicos realizados no arranjo e estágios em empresas fornecedoras e, principalmente, em clientes. Esse aspecto merece destaque, uma vez que essa rede é formada por empresas que prestam serviços industriais e etapas do processo produtivo, e a realização de estágios junto aos clientes é de grande importância para o conhecimento das especificidades de cada subcontratante. Nas empresas da Rede Tipo 3, a importância de atividades de treinamento e capacitação de recursos humanos, de modo geral, é reduzida.

A tabela 3 apresenta os indicadores relacionados à aprendizagem para cada tipo de rede. Em relação à aprendizagem interna, todas as redes, com exceção da Tipo 2, apresentam indicadores acima da média, tanto em relação à intensidade quanto à formalização. Já no aprendizado externo, a Rede Tipo 2 apresenta os melhores indicadores relacionados aos agentes produtivos e aos agentes de ciência e tecnologia, sendo todos eles consideravelmente superiores à média da amostra. No tocante ao aprendizado relacionado às

Tabela 3: Análise de cluster das redes segundo os indicadores de aprendizagem, valores médios de cada cluster nos indicadores

\begin{tabular}{|c|c|c|c|c|c|c|c|c|}
\hline \multirow{2}{*}{$\begin{array}{l}\text { Indicadores } \\
\text { de esforço }\end{array}$} & Rede 1-17 & Empresas & Rede 2-34 & Empresas & Rede 3-24 & Empresas & Amostra-71 & Empresas \\
\hline & Média & $\begin{array}{l}\text { Desvio } \\
\text { padrão }\end{array}$ & Média & $\begin{array}{l}\text { Desvio } \\
\text { padrão }\end{array}$ & Média & $\begin{array}{l}\text { Desvio } \\
\text { padrão }\end{array}$ & Média & $\begin{array}{l}\text { Desvio } \\
\text { padrão }\end{array}$ \\
\hline \multicolumn{9}{|l|}{ Interna } \\
\hline $\begin{array}{l}\text { YA1 - Aprendizado } \\
\text { Interno }\end{array}$ & 0,6926 & 0,2534 & 0,5926 & 0,2556 & 0,6896 & 0,2719 & 0,6327 & 0,2493 \\
\hline $\begin{array}{l}\text { YA2 - Estrutura do } \\
\text { Aprendizado Interno }\end{array}$ & 0,5221 & 0,2430 & 0,5037 & 0,2373 & 0,5208 & 0,2139 & 0,5088 & 0,2259 \\
\hline \multicolumn{9}{|l|}{ Externa } \\
\hline $\begin{array}{l}\text { YA3 - Aprendizado } \\
\text { Ext./Agentes Produtivos }\end{array}$ & 0,3941 & 0,1240 & 0,4197 & 0,1749 & 0,3518 & 0,1124 & 0,3897 & 0,1457 \\
\hline $\begin{array}{l}\text { YA4 - Estrutura Aprend. } \\
\text { Ext. / Agentes Produtivos }\end{array}$ & 0,3655 & 0,1470 & 0,3845 & 0,1471 & 0,3423 & 0,1519 & 0,3622 & 0,1445 \\
\hline $\begin{array}{l}\text { YA5 - Aprendizado Ext./ } \\
\text { Agentes de C\&T }\end{array}$ & 0,1500 & 0,2039 & 0,2809 & 0,2664 & 0,1958 & 0,2096 & 0,2282 & 0,2300 \\
\hline $\begin{array}{l}\text { YA6 - Estrutura Apr. Ext./ } \\
\text { Agentes de C\&T }\end{array}$ & 0,1912 & 0,2619 & 0,3272 & 0,3031 & 0,2656 & 0,2588 & 0,2729 & 0,2650 \\
\hline $\begin{array}{l}\text { YA7 - Aprendizado. Ext./ } \\
\text { Demais Fontes de Informação }\end{array}$ & 0,5333 & 0,1611 & 0,5176 & 0,1940 & 0,5042 & 0,1933 & 0,5085 & 0,1788 \\
\hline $\begin{array}{l}\text { YA8 - Estrutura Apr. Ext./ } \\
\text { Demais Fontes de Informação }\end{array}$ & 0,5686 & 0,1450 & 0,5564 & 0,1820 & 0,5833 & 0,2026 & 0,5669 & 0,1729 \\
\hline
\end{tabular}

Fonte: Pesquisa de campo, 2003. 
Tabela 4: Análise de cluster das redes segundo os indicadores de cooperação, valores médios de cada cluster nos indicadores

\begin{tabular}{|c|c|c|c|c|c|c|c|c|}
\hline \multirow{2}{*}{$\begin{array}{l}\text { Indicadores de } \\
\text { Aprendizagem }\end{array}$} & \multicolumn{2}{|c|}{$\begin{array}{l}\text { Rede 1-17 } \\
\text { Empresas }\end{array}$} & \multicolumn{2}{|c|}{$\begin{array}{l}\text { Rede } 2-34 \\
\text { Empresas }\end{array}$} & \multicolumn{2}{|c|}{$\begin{array}{l}\text { Rede 3-24 } \\
\text { Empresas }\end{array}$} & \multicolumn{2}{|c|}{$\begin{array}{c}\text { Amostra-71 } \\
\text { Empresas }\end{array}$} \\
\hline & Média & $\begin{array}{l}\text { Desvio } \\
\text { Padrão }\end{array}$ & Média & $\begin{array}{l}\text { Desvio } \\
\text { Padrão }\end{array}$ & Média & $\begin{array}{l}\text { Desvio } \\
\text { Padrão }\end{array}$ & Média & $\begin{array}{l}\text { Desvio } \\
\text { Padrão }\end{array}$ \\
\hline $\begin{array}{l}\text { YC1 - Cooperação } \\
\text { Agentes Produtivos }\end{array}$ & 0,1471 & 0,2076 & 0,2710 & 0,2372 & 0,1815 & 0,1994 & 0,1954 & 0,2125 \\
\hline $\begin{array}{l}\text { YC2 - Estrutura da } \\
\text { Coop. Agen. Prod. }\end{array}$ & 0,1218 & 0,1952 & 0,2584 & 0,2279 & 0,1637 & 0,1890 & 0,1831 & 0,2069 \\
\hline $\begin{array}{l}\text { YC3 - Cooperação } \\
\text { Agentes de C\&T }\end{array}$ & 0,0765 & 0,1416 & 0,1125 & 0,1989 & 0,1104 & 0,1968 & 0,0954 & 0,1719 \\
\hline $\begin{array}{l}\text { YC4 - Estrutura da } \\
\text { Coop. Agen. C\&T } \\
\end{array}$ & 0,0735 & 0,1174 & 0,1103 & 0,2171 & 0,0885 & 0,1585 & 0,0968 & 0,1820 \\
\hline $\begin{array}{l}\text { Y24 - Cooperação } \\
\text { Demais Agentes } \\
\end{array}$ & 0,0706 & 0,1356 & 0,1221 & 0,2000 & 0,0813 & 0,1147 & 0,0961 & 0,1597 \\
\hline $\begin{array}{l}\text { Y25 - Estrutura da } \\
\text { Coop. Dem. Agen. }\end{array}$ & 0,1103 & 0,1971 & 0,1544 & 0,2666 & 0,1354 & 0,1912 & 0,1320 & 0,2205 \\
\hline
\end{tabular}

Tabela 5: Análise de cluster das redes segundo os indicadores de desempenho, valores médios de cada cluster nos indicadores

\begin{tabular}{|c|c|c|c|c|c|c|c|c|}
\hline \multirow{2}{*}{$\begin{array}{l}\text { Indicadores de } \\
\text { Aprendizagem }\end{array}$} & \multicolumn{2}{|c|}{$\begin{array}{l}\text { Rede } 1-17 \\
\text { Empresas }\end{array}$} & \multicolumn{2}{|c|}{$\begin{array}{l}\text { Rede } 2-34 \\
\text { Empresas }\end{array}$} & \multicolumn{2}{|c|}{$\begin{array}{c}\text { Rede 3-24 } \\
\text { Empresas }\end{array}$} & \multicolumn{2}{|c|}{$\begin{array}{c}\text { Amostra-71 } \\
\text { Empresas }\end{array}$} \\
\hline & Média & $\begin{array}{l}\text { Desvio } \\
\text { Padrão }\end{array}$ & Média & $\begin{array}{l}\text { Desvio } \\
\text { Padrão }\end{array}$ & Média & $\begin{array}{l}\text { Desvio } \\
\text { Padrão }\end{array}$ & Média & $\begin{array}{l}\text { Desvio } \\
\text { Padrão }\end{array}$ \\
\hline $\begin{array}{l}\text { YD1 - Introdução } \\
\text { de Inovação }\end{array}$ & 0,3431 & 0,2261 & 0,3186 & 0,2550 & 0,4097 & 0,1665 & 0,3451 & 0,2242 \\
\hline $\begin{array}{l}\text { YD2 - Impacto } \\
\text { da Inovação }\end{array}$ & 0,4063 & 0,2429 & 0,4097 & 0,2078 & 0,3955 & 0,1924 & 0,4024 & 0,2093 \\
\hline $\begin{array}{l}\text { YD3 - Resultados } \\
\text { da Cooperação }\end{array}$ & 0,2700 & 0,3281 & 0,3041 & 0,3015 & 0,2963 & 0,2940 & 0,2686 & 0,2865 \\
\hline $\begin{array}{l}\text { YD4 - Melhora nas } \\
\text { Capacitações }\end{array}$ & 0,3600 & 0,4037 & 0,4418 & 0,3608 & 0,3675 & 0,3292 & 0,3792 & 0,3568 \\
\hline
\end{tabular}

Fonte: Pesquisa de campo, 2003.

demais fontes de informação, a Rede Tipo 1 apresenta os melhores indicadores quanto à intensidade, e a Rede Tipo 3, no tocante à formalização dessa forma de aprendizagem.

Portanto, em relação à aprendizagem, é possível perceber diferenças relevantes entre as redes, com destaque para a maior relevância do aprendizado interno nas redes Tipo 1 e Tipo 3. O aprendizado externo possui uma maior relevância na Rede Tipo 2, refletindo a maior necessidade das empresas inseridas de absorverem conhecimentos externos. 
Os indicadores relacionados à cooperação são apresentados na tabela 4. Constata-se que na Rede Tipo 2 todos os indicadores de cooperação são superiores às demais redes, com destaque para a cooperação com agentes produtivos. Essa análise reforça as características dessa rede, na qual as empresas estabelecem múltiplas relações, tanto voltadas para o aprendizado quanto para a cooperação com agentes externos. No entanto, a importância atribuída pelas empresas às atividades cooperativas é, de forma geral, muito reduzida no âmbito do arranjo, sendo também realizadas predominantemente de maneira informal.

A tabela 5 apresenta os indicadores de desempenho inovativo para cada tipo de rede. As empresas da Rede Tipo 3 possuem um desempenho comparativo mais elevado em relação à introdução de inovações. O impacto da atividade inovativa para as empresas é similar para todos os tipos de rede, mas apenas na Rede Tipo 3 esse se encontra abaixo da média. As empresas da Rede Tipo 2 apresentam os melhores indicadores relacionados aos resultados da cooperação e à melhora nas capacitações.

A figura 3 apresenta o percentual de empresas de cada rede e o tipo de inovação introduzida. Na Rede Tipo 1, o desempenho inovativo é mais elevado na imitação de produtos e processos, nas inovações em relação ao desenho do produto e na implementação de inovações organizacionais. As empresas da Rede Tipo 2 introduzem um nível maior de inovação nos processos produtivos e nas inovações organizacionais. Já as empresas da Rede Tipo 3 são aquelas que, de forma geral, mais introduzem inovações, destacando-se principalmente a inovação em produtos, que não se resume apenas à imitação, já que 58,3\% das empresas inseridas nessa rede lançaram um produto novo para o mercado nacional. Vale salientar que a inovação no desenho do produto, na Rede Tipo 3, também apresenta um percentual elevado (62,5\%). Portanto, é possível concluir que, comparativamente às outras redes, a Rede Tipo 3 apresenta um desempenho mais elevado na introdução de inovações.

Os impactos resultantes da introdução de inovações são apresentados na figura 4. Para as empresas da Rede Tipo 1, os principais impactos envolvem o aumento da qualidade dos produtos e a manutenção da participação nos mercados de atuação, seguidos pelo aumento da gama de produtos ofertados. Já nas empresas da Rede Tipo 2, o aumento da produtividade é o principal impacto gerado pela introdução de inovações, com destaque também 
Figura 3: Porcentagem de empresas e tipo de inovaçãointroduzida em cada rede

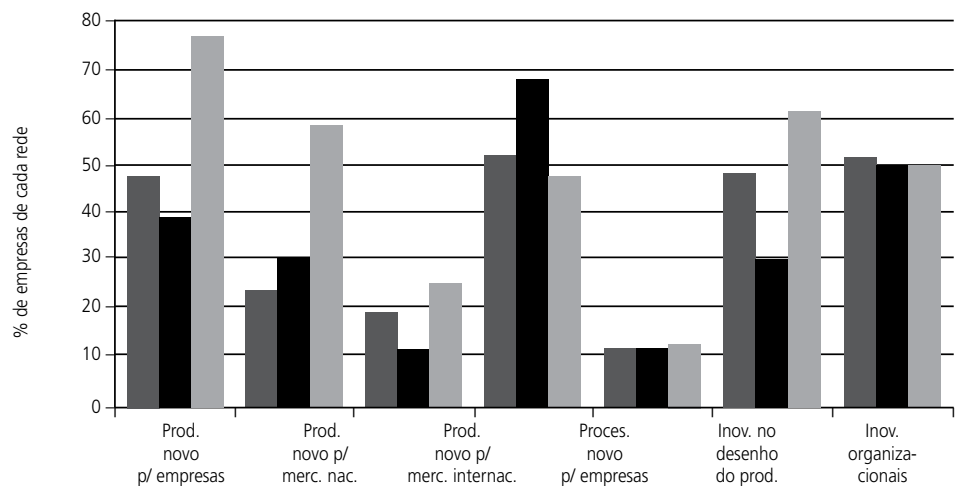

Tipo de inovação introduzida pelas empresas

Figura 4: Porcentagem de empresas e impacto das inovações introduzidas

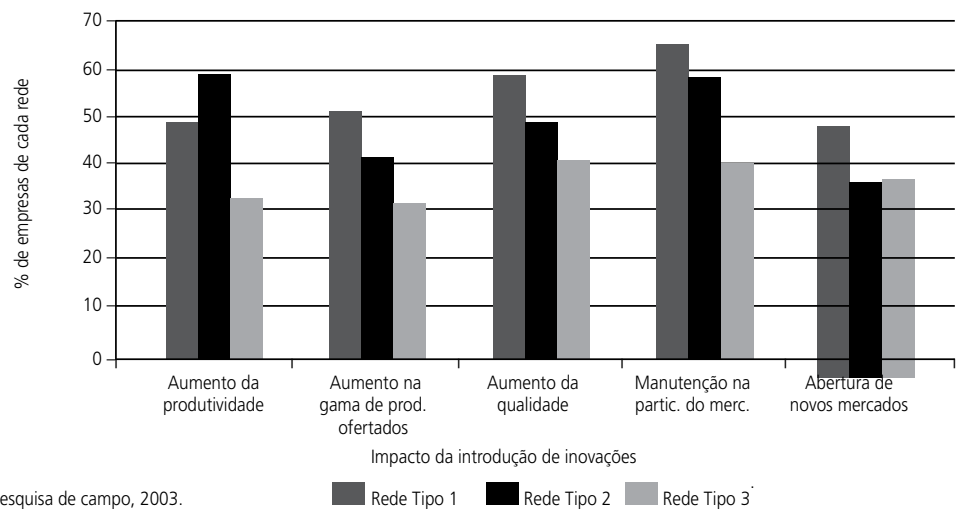

Fonte: Pesquisa de campo, 2003

Figura 5: Porcentagem de empresas e melhora nas capacitações derivadas dos processos de cooperação e aprendizagem

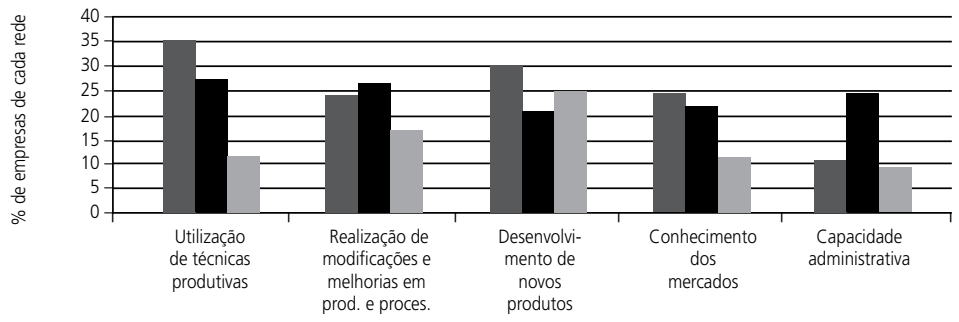

Melhora na capacitação das empresas 
para a manutenção da participação nos mercados de atuação. Na Rede Tipo 3, o efeito da introdução de inovações está relacionado à manutenção da participação das empresas nos mercados. Com base nessas evidências, é possível sugerir que a introdução de inovações gera impactos mais acentuados nas Redes Tipos 1 e 2, permitindo que as empresas nelas inseridas mantenham suas participações nos mercados de atuação, aumentem sua produtividade e a qualidade dos produtos gerados.

O impacto dos processos de aprendizagem e cooperação na melhoria das capacitações das empresas é apresentado na figura 5. Nas empresas da Rede Tipo 1, esses processos elevaram principalmente as capacitações relacionadas à melhor utilização das técnicas produtivas e ao desenvolvimento de novos produtos. Na Rede Tipo 2, as empresas elevaram suas capacitações relacionadas a modificações e melhorias em produtos e processos, bem como aquelas voltadas para a capacidade administrativa. Na Rede Tipo 3, esses processos afetaram principalmente as capacitações relacionadas ao desenvolvimento de novos produtos. Observando-se essas informações em conjunto, verifica-se um maior impacto nas capacitações das empresas inseridas na Rede Tipo 1, em virtude dos processos de cooperação e aprendizagem.

\section{CONSIDERAÇÕES FINAIS}

Procurou-se nesta análise estudar as formas de inserção das micro e pequenas empresas em redes tecnoprodutivas existentes em aglomerações industriais, observando-se o caso da indústria elotrometal-mecânica na microrregião de Joinville. Para tanto foi feita uma análise qualitativa para identificar os diferentes tipos de redes existentes no local e aplicou-se uma análise multivariada de cluster com base em um conjunto de indicadores, de forma a comparar as características do esforço inovativo das empresas e os processos de aprendizagem e de cooperação. Esses indicadores foram relacionados com os de desempenho inovativo, de modo a caracterizar a "dinâmica" de construção de competências no arranjo investigado.

As evidências apresentadas sugerem que, no caso do arranjo eletrometalmecânico da microrregião de Joinville, as sinergias proporcionadas pela proximidade e pelas intensas interações entre os agentes possibilitaram o desenvolvimento de um sistema produtivo localizado com forte potencial inovador. Partindo dessas evidências e considerando os procedimentos de- 
senvolvidos ao longo da análise, a contribuição do artigo desdobra-se em três campos principais.

No plano metodológico, procurou-se avançar no sentido de uma maior integração das dimensões qualitativa e quantitativa de análises que utilizam o conceito de "redes tecnoprodutivas" como recorte analítico fundamental. Acredita-se, nesse sentido, que os procedimentos utilizados podem ser reproduzidos em outras situações, de modo a auxiliar no detalhamento da conformação estrutural - e institucional — dessas redes em cada situação particular, com base em critérios que privilegiem os múltiplos tipos de relacionamentos e as formas de aprendizado a eles vinculados, que teriam impactos diretos sobre a construção de competências e sobre a capacitação e o desempenho inovativo dos agentes integrados a nesses arranjos.

Em segundo lugar, a análise realizada fornece uma importante ilustração empírica da diversidade estrutural daquelas redes em cada contexto industrial particular. De fato, considerando a situação observada no setor eletrometal-mecânico na região de Joinville, foi possível observar uma grande diversidade entre distintas "redes" no tocante a aspectos como a natureza das atividades inovativas desenvolvidas, as atividades de treinamento e capacitação de recursos humanos, as formas de aprendizado mais relevantes, a intensidade da cooperação e o desempenho inovativo (avaliado tanto em termos do tipo como do impacto das inovações introduzidas). Essa diversidade reforça a percepção de que as "redes tecnoprodutivas" não devem ser concebidas como estruturas monolíticas, mas sim como estruturas intrinsecamente complexas e heterogêneas, cujos agentes possuem características assimétricas, vinculadas à consolidação de competências técnicas e cognitivas específicas.

Em terceiro lugar, a análise possibilitou observar características específicas da inserção das empresas no âmbito de um arranjo produtivo, as quais podem orientar a formulação de políticas industriais e tecnológicas descentralizadas, que considerem as especificidades das interações em redes. Nesse sentido, há indícios de que a conformação dessas múltiplas redes é responsável pela geração de uma determinada "dinâmica" capaz de gerar importantes desdobramentos sobre a região e o setor nos quais as mesmas se encontram inseridas. O seu monitoramento ao longo do tempo — identificando-se problemas e oportunidades — pode, assim, se constituir em um importante instrumento de estímulo ao reforço de seu potencial inovativo e de seu potencial para alavancar o desenvolvimento econômico local. 


\section{ANEXO I - DESCRIÇÃO DOS INDICADORES}

A partir de um conjunto selecionado de perguntas que constam do questionário aplicado nas empresas, procurou-se transformar atributos qualitativos, tais como a importância atribuída pela empresa a determinado evento, em quantitativos, ou seja, encontrando um valor entre 0 e 1 que expressasse a opinião da empresa sobre cada evento. ${ }^{28}$ Como se pode notar os indicadores mensuram a importância atribuída de forma individual, ou seja, para cada empresa entrevistada. Estes podem ser divididos em quatro grupos:

(I) Indicadores de esforço tecnológico: Expressam as características dos esforços tecnológicos desenvolvidos pelas empresas. O indicador YE1 mede a forma e a freqüência com a qual a firma desenvolve as atividades inovativas. Já o indicador YE2 refere-se à importância percebida pelas empresas da realização de atividades de treinamento e capacitação de RH. O quadro Al apresenta os eventos captados por cada indicador.

(II) Indicadores de aprendizagem tecnológica: Medem a importância atribuída pela empresa às fontes de informação para a aprendizagem e se essas informações são obtidas de maneira formal ou informal. O quadro A2 resume os eventos captados por cada indicador.

(III) Indicadores de cooperação tecnológica: Este conjunto de indicadores procura medir a importância atribuída pelas empresas às ações cooperativas desenvolvidas com diversos agentes, além do grau de estruturação destas ações. Os eventos/agentes relacionados a cada indicador são apresentados no quadro A3.

(IV) Indicadores de desempenho: Este conjunto de indicadores procura captar qual o desempenho das empresas analisadas quanto à introdução de inovações e aos resultados obtidos com os processos de treinamento, aprendizado e cooperação. Os eventos captados por cada indicador desse conjunto estão presentes no quadro A4.

Todos os indicadores sugeridos neste trabalho seguem um raciocínio matemático simples e semelhante. Os indicadores que expressam a importância percebida pelas empresas a um determinado conjunto de eventos (YE2, YA1, YA3, YA5, YA7, YC1, YC3, YC5, YD2, YD3 e YD4) foram estimados da seguinte forma: 


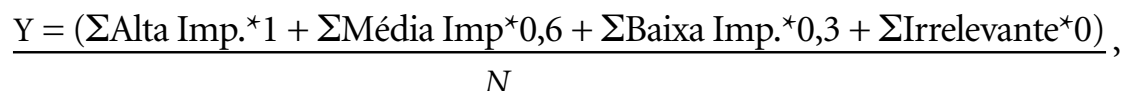

em que $N$ representa o número de eventos analisado em cada indicador. Já os indicadores referentes ao grau de formalização, tanto da aprendizagem quanto da cooperação (YA2, YA4, YA6, YA8, YC2, YC4 e YC6), seguem o seguinte lógica:

$$
\frac{\mathrm{Y}=\left(\sum \text { Formal }^{\star} 1+\sum \text { Informal }^{\star} 0\right)}{N},
$$

em que $N$ representa novamente o número de eventos. $\mathrm{O}$ indicador que mede a forma e a freqüência da atividade inovativa (YE1) foi estimado da forma seguinte:

$$
\frac{\text { YE }=\left(\Sigma \text { Desenv. Rotineir. }{ }^{\star} 1+\sum \text { Desenv. Ocasio. }{ }^{\star} 0,5+\sum \text { Não Desenv }{ }^{\star} 0\right)}{8} ;
$$

note-se que, para esse indicador, o número de eventos avaliados é igual a 8. Por fim, o indicador relacionado à introdução de inovações pelas empresas (YD1) pode ser assim apresentado:

$$
\frac{\mathrm{YD} 1=\left(\sum N^{0} \operatorname{de} \operatorname{Sim}^{\star} 1+\sum N^{0} \text { de } N a ̃ o^{\star} 0\right)}{11}
$$

em que o "sim" representa que a empresa introduziu uma inovação nos eventos avaliados, e o "não", que não introduziu inovação nos quesitos. 


\section{Quadro A1: 0 Eventos captados pelos indicadores de esforço tecnológico}

\begin{tabular}{|c|c|}
\hline Indicador & Eventos \\
\hline \multirow{8}{*}{$\begin{array}{l}\text { YE1 - Forma } \\
\text { e freqüência } \\
\text { da atividade } \\
\text { inovativa }\end{array}$} & Pesquisa e desenvolvimento (P\&D) na sua empresa; \\
\hline & Aquisição externa de P\&D; \\
\hline & $\begin{array}{l}\text { Aquisição de máquinas e equipamentos que implicaram significativas melhorias ino- } \\
\text { vativas tecnológicas de produtos/processos ou que estão associados aos novos } \\
\text { produtos/processos; }\end{array}$ \\
\hline & $\begin{array}{l}\text { Aquisição de outras tecnologias (softwares, licenças ou acordos de transferência de } \\
\text { tecnologias, tais como patentes, marcas, segredos industriais); }\end{array}$ \\
\hline & $\begin{array}{l}\text { Projeto industrial ou desenho industrial associados a produtos/processos tecnologica- } \\
\text { mente novos ou significativamente melhorados; }\end{array}$ \\
\hline & $\begin{array}{l}\text { Programa de treinamento orientado à introdução de produtos/processos tecnologica- } \\
\text { mente novos ou significativamente melhorados; }\end{array}$ \\
\hline & $\begin{array}{l}\text { Programas de gestão da qualidade ou de modernização organizacional, tais como: } \\
\text { qualidade total, reengenharia de processos administrativos, desverticalização do } \\
\text { processo produtivo, métodos de just in time etc. }\end{array}$ \\
\hline & $\begin{array}{l}\text { Novas formas de comercialização e distribuição para o mercado de produtos novos ou } \\
\text { significativamente melhorados. }\end{array}$ \\
\hline \multirow{9}{*}{$\begin{array}{l}\text { YE2 - Esforço } \\
\text { de treinamento } \\
\text { e capacitação de } \\
\text { recursos humanos }\end{array}$} & Treinamento na empresa; \\
\hline & Treinamento em cursos técnicos realizados no arranjo; \\
\hline & Treinamento em cursos técnicos fora do arranjo; \\
\hline & Estágios em empresas fornecedoras ou clientes; \\
\hline & Estágios em empresas do grupo; \\
\hline & Contratação de técnicos/engenheiros de outras empresas do arranjo; \\
\hline & Contratação de técnicos/engenheiros de empresas fora do arranjo; \\
\hline & Absorção de formandos dos cursos universitários localizados no arranjo ou próximo; \\
\hline & Absorção de formandos dos cursos técnicos localizados no arranjo ou próximo. \\
\hline
\end{tabular}

Fonte: Elaboração própria. 


\section{Quadro A2: Eventos captados pelos indicadores de aprendizagem tecnológico}

\begin{tabular}{ll}
\hline Indicador & Eventos/fontes de informação \\
\hline YA1 - & Departamento de P\&D; \\
\begin{tabular}{ll} 
Aprendizagem & Área de produção; \\
interna & $\begin{array}{l}\text { Áreas de vendas e marketing; } \\
\text { Áreas de serviços de atendimento ao cliente. }\end{array}$ \\
\hline YA2 - Grau de & \\
da formalização da & Se as fontes de aprendizagem do indicador YA1 são formais ou informais \\
aprendizagem interna & \\
\hline YA3 - Aprendizado & Outras empresas dentro do grupo; \\
com outros & Empresas associadas (joint venture); \\
agentes produtivos & Fornecedores de insumos (equipamentos, materiais); \\
& Clientes; \\
& Concorrentes; \\
& Outras empresas do setor; empresas de consultoria.
\end{tabular} \\
\hline
\end{tabular}

YA4 - Grau de

formalização do

aprendizado com Se as fontes de aprendizagem do indicador YA3 são formais ou informais.

outros agentes

produtivos

\begin{tabular}{|c|c|}
\hline $\begin{array}{l}\text { YA5 - Aprendizagem } \\
\text { com agentes } \\
\text { de C\&T }\end{array}$ & $\begin{array}{l}\text { Universidades; } \\
\text { Institutos de pesquisa; } \\
\text { Centros de capacitação profissional, de assistência técnica e de manutenção; } \\
\text { Instituições de testes, ensaios e certificações. }\end{array}$ \\
\hline $\begin{array}{l}\text { YA6 - Grau de } \\
\text { formalização } \\
\text { do aprendizado } \\
\text { com agentes de C\&T }\end{array}$ & Se as fontes de aprendizagem do indicador YA5 são formais ou informais. \\
\hline $\begin{array}{l}\text { YA7 - Aprendizado } \\
\text { por outras fontes } \\
\text { de informação }\end{array}$ & $\begin{array}{l}\text { Licenças, patentes e know-how } \\
\text { Conferências, seminários } \\
\text { Cursos e publicações especializadas; feiras, exibições e lojas; encontros de lazer (clu- } \\
\quad \text { bes, restaurantes etc.); } \\
\text { Associações empresariais locais (inclusive consórcios de exportações); } \\
\text { Informações de rede baseadas na Internet ou computador). }\end{array}$ \\
\hline
\end{tabular}

YA8 - Grau de

formalização do

aprendizado por Se as fontes de aprendizagem do indicador YA7 são formais ou informais.

outras fontes

de informação

Fonte: Elaboração própria. 


\section{Quadro A3: Eventos captados pelos indicadores de cooperação tecnológica}

\begin{tabular}{|c|c|}
\hline Indicador & Eventos/agentes envolvidos na cooperação \\
\hline $\begin{array}{l}\text { YC1 - Cooperação } \\
\text { com agentes } \\
\text { produtivos }\end{array}$ & $\begin{array}{l}\text { Outras empresas dentro do grupo; } \\
\text { Empresas associadas (joint venture); } \\
\text { Fornecedores de insumos (equipamentos, materiais); } \\
\text { Clientes; concorrentes; } \\
\text { Outras empresas do setor; empresas de consultoria. }\end{array}$ \\
\hline $\begin{array}{l}\text { YC2 - Grau de } \\
\text { formalização da } \\
\text { cooperação com } \\
\text { agentes produtivos }\end{array}$ & $\begin{array}{l}\text { Se as ações cooperativas desenvolvidas com os agentes do indicador YC1 são formais } \\
\text { ou informais. }\end{array}$ \\
\hline $\begin{array}{l}\text { YC3 - Cooperação } \\
\text { com agentes } \\
\text { de C\&T }\end{array}$ & $\begin{array}{l}\text { Universidades; } \\
\text { Institutos de pesquisa; } \\
\text { Centros de capacitação profissional, de assistência técnica e de manutenção; } \\
\text { Instituições de testes, ensaios e certificações. }\end{array}$ \\
\hline $\begin{array}{l}\text { YC4 - Grau de } \\
\text { formalização da } \\
\text { cooperação com } \\
\text { agentes C\&T }\end{array}$ & $\begin{array}{l}\text { Se as ações cooperativas desenvolvidas com os agentes do indicador YC3 são formais } \\
\text { ou informais. }\end{array}$ \\
\hline $\begin{array}{l}\text { YC5 - Cooperação } \\
\text { com outros } \\
\text { agentes do APL }\end{array}$ & $\begin{array}{l}\text { Representação; } \\
\text { Entidades sindicais; } \\
\text { Órgãos de apoio e promoção; } \\
\text { Agentes financeiros. }\end{array}$ \\
\hline $\begin{array}{l}\text { YC6 - Grau de } \\
\text { formalização da } \\
\text { cooperação com } \\
\text { outros agentes } \\
\text { do APL }\end{array}$ & $\begin{array}{l}\text { Se as ações cooperativas desenvolvidas com os agentes do indicador YC } 5 \text { são formais } \\
\text { ou informais. }\end{array}$ \\
\hline
\end{tabular}

Fonte: Elaboração própria. 


\section{Quadro A4: Eventos captados pelos indicadores de cooperação tecnológica}

\begin{tabular}{|c|c|}
\hline Indicador & Eventos \\
\hline $\begin{array}{l}\text { YD1 - Introdução } \\
\text { de inovações }\end{array}$ & $\begin{array}{l}\text { Produto novo para o mercado internacional; } \\
\text { Processo novo para o setor de atuação; } \\
\text { Produto novo para a empresa, mas já existente no mercado; } \\
\text { Produto novo para o mercado nacional; } \\
\text { Processo tecnologicamente novo para a empresa, mas já existente no setor; } \\
\text { Criação ou melhoria substancial, do ponto de vista tecnológico, do modo de } \\
\qquad \text { acondicionamento dos produtos; } \\
\text { Inovação no desenho do produto; } \\
\text { Implementação de técnicas avançadas de gestão; } \\
\text { Implementação de significativas mudanças na estrutura organizacional; } \\
\text { Mudanças significativas nos conceitos e/ou práticas de marketing; } \\
\text { Mudanças significativas nos conceitos e/ou práticas de comercialização; } \\
\text { Implementação de novos métodos e gerenciamento, visando a atender a normas } \\
\text { de certificação (Iso } 9000, \text { Iso } 14000 \text { etc.). }\end{array}$ \\
\hline $\begin{array}{l}\text { YD2 - Resultados } \\
\text { das atividades } \\
\text { inovativas }\end{array}$ & $\begin{array}{l}\text { Aumento da produtividade da empresa; } \\
\text { Ampliação da gama de produtos ofertados; } \\
\text { Aumento da qualidade dos produtos; } \\
\text { Permitiu que a empresa mantivesse a sua participação nos mercados de atuação; } \\
\text { Aumento da participação no mercado interno da empresa; } \\
\text { Aumento da participação no mercado externo da empresa; } \\
\text { Permitiu que a empresa abrisse novos mercados; } \\
\text { Permitiu a redução de custos do trabalho; } \\
\text { Permitiu a redução de custos de insumos; } \\
\text { Permitiu a redução do consumo de energia; } \\
\text { Permitiu o enquadramento em regulações e normas padrão relativas ao mercado } \\
\text { interno; } \\
\text { Permitiu o enquadramento em regulações e normas padrão relativas ao mercado } \\
\quad \text { externo; } \\
\text { Permitiu reduzir o impacto sobre o meio ambiente. }\end{array}$ \\
\hline $\begin{array}{l}\text { YD3 - Resultado } \\
\text { obtido com } \\
\text { a cooperação }\end{array}$ & $\begin{array}{l}\text { Melhoria na qualidade dos produtos; } \\
\text { Desenvolvimento de novos produtos; } \\
\text { Melhoria nos processos produtivos; } \\
\text { Melhoria nas condições de fornecimento dos produtos; } \\
\text { Introdução de inovações organizacionais; } \\
\text { Melhoria nas condições de comercialização; } \\
\text { Novas oportunidades de negócios; } \\
\text { Promoção do nome/marca da empresa no mercado nacional; } \\
\text { Maior inserção da empresa no mercado externo. }\end{array}$ \\
\hline $\begin{array}{l}\text { YD4 - Resultados } \\
\text { obtidos com } \\
\text { os processos } \\
\text { de aprendizagem } \\
\text { e treinamento }\end{array}$ & $\begin{array}{l}\text { Melhor utilização das técnicas produtivas; } \\
\text { Maior capacitação para a realização de modificações e melhorias em produtos } \\
\quad \text { e processos; } \\
\text { Melhor capacitação para desenvolver novos produtos e processos; } \\
\text { Maior conhecimento sobre os mercados de atuação da empresa; } \\
\text { Melhor capacitação administrativa. }\end{array}$ \\
\hline
\end{tabular}




\section{NOTAS}

1. O Quociente Locacional (QL) nos dá uma noção comparativa da especialização da microrregião em função do país. Em casos em que o QL é superior a 1, a especialização da microrregião nessa atividade é superior à especialização do Brasil (Britto \& Albuquerque, 2002). Para a microrregião de Joinville, os QLs dos segmentos de atividades relacionadas à indústria eletrometal-mecânica são: Metalurgia, 4,27; Mecânica, 7,04; Material Elétrico e de Comunicação, 5,77; e Material de Transporte, 2,35.

2. Essa característica tende a ser ainda mais marcante no caso brasileiro, dada a "heterogeneidade estrutural" inerente à base industrial, que se reflete em expressivos diferenciais de eficiência e capacitação em termos inter e intra-setoriais (Ferraz et alli, 1996).

3. Disponível na página: http://www.arranjosmpes.ufsc.br.

4. Descritos no Anexo I.

5. Essa análise avalia um conjunto de relações interdependentes, sem fazer distinção entre variáveis dependentes e independentes. Ela permite classificar objetos, no caso empresas, em grupos relativamente homogêneos, com base no conjunto de variáveis consideradas (Malhotra, 2001). O software utilizado foi o Statistica 6.0, que nos dá como resultado o valor do indicador no centro de cada cluster.

6. Materiais diretos são peças, componentes e/ou subsistemas que são integrados ao produto final.

7. Materiais indiretos são aqueles utilizados durante os processos produtivos, como moldes e ferramentas, por exemplo.

8. Materiais indiretos são aqueles utilizados durante os processos produtivos, como moldes, ferramentas e matrizes, por exemplo.

9. Pesquisa de campo.

10. A complexidade e a modularidade dos bens produzidos por essas empresas influenciam significativamente nas estratégias.

11. Principalmente nas grandes e médias empresas cujos produtos possuem um conteúdo tecnológico mais elevado.

12. Dependendo da importância do componente fornecido, essas auditorias são anuais nos componentes mais críticos e de dois em dois anos nos menos críticos.

13. Em que o produto possui um conteúdo tecnológico mais reduzido.

14. Por amostragem.

15. Por exemplo, uma pequena empresa fornecedora de peças estampadas, envia lotes de peças três vezes ao dia, há uma grande empresa local, uma no início de cada turno, tendo de adaptar sua produção a essas exigências.

16. Geralmente esses bens são fornecidos por grandes empresas que dificilmente se submetem a todas as exigências requeridas às MPEs. 
17. Sem especificação das quantidades.

18. É óbvio que, no caso de relacionamentos desenvolvidos entre MPEs e grandes empresas, estas últimas possuem um poder de barganha maior.

19. Apesar da importância do preço na seleção dos fornecedores, esse é apenas um critério com relevância idêntica aos apresentados anteriormente, nesse tipo de rede.

20. Por exemplo, em uma microempresa que fornece linhas de máquinas de solda para uma grande empresa, esta última desloca técnicos especializados para o desenvolvimento das máquinas e para a execução de testes e ensaios antes de elas serem entregues.

21. O departamento que demanda o material (geralmente a engenharia de processos) possui a autonomia de contratar o serviço, desde que o valor do material não ultrapasse um montante estipulado. Dessa forma, os responsáveis pelos processos, baseados em um conhecimento prévio das empresas que prestam esses serviços, tomam os preços e decidem quem contratar.

22. Um exemplo desses casos é um grupo de sete MPEs, subcontratadas para a prestação de serviços de acabamentos superficiais para uma grande empresa local. O grau de articulação entre a empresa subcontratante e as empresas subcontratadas é tão elevado que, pelo incentivo da grande empresa, surgiu um núcleo setorial auxiliado por uma instituição local (a Ajorpeme), para troca de experiências e informações entre as empresas subcontratadas.

23. Em alguns casos específicos em que são produzidos materiais indiretos com um grau de complexidade maior e/ou com uma posição mais estratégica nos processos, a variável preço é posta em segundo plano e as capacitações das MPEs, bem como o know-how específico, passam a ser mais influentes na decisão de subcontratação.

24. Perceberam-se na pesquisa de campo alguns casos em que uma empresa de usinagem foi contratada para prestar um serviço para o qual ela não tinha condições de atender os volumes solicitados. A solução encontrada foi subcontratar outras MPEs locais, para que, em conjunto, pudessem atender ao pedido.

25. Como no caso do consórcio de exportação, em que a articulação entre as empresas é exercida por um escritório de exportação.

26. É importante deixar claro que uma mesma MPE pode e, em vários casos, participa de mais de um tipo de rede, bem como existe um número mais reduzido de micro e pequenas empresas que não participam de nenhum tipo de rede local e atuam no APL de forma isolada.

27. Essa atividade em particular possui uma elevada importância para as empresas dos três tipos de rede.

28. Com exceção dos indicadores referentes à forma e à freqüência da atividade inovativa (YE1) e o do de introdução de inovação pelas empresas (YD1) que medem, respectivamente, se a empresa desenvolveu ou não e com que freqüência uma atividade inovativa e se a empresa introduziu ou não um determinado tipo de inovação. Além destes dois indicadores, destaca-se também, que os indicadores referentes a formalização da aprendizagem e da cooperação, expressam o grau de formalização destas atividades. 


\section{REFERÊNCIAS BIBLIOGRÁFICAS}

BANDT, J. Aproche meso-éconimique de la dynamique industrielle. Revue d'Economie Industrielle, n. 49, 3er trimestre, 1989.

BECATINI, G. Sectors and or districts: some remarkes on the conceptual foundation of industrial economics. In: COCCO, G. et al. (2002) Empresários e empregos nos nossos territórios produtivos: o caso da Terceira Itália. 2. ed. Rio de Janeiro: DP\&A. (1989)

BRITTO, J. N. de P. Características estruturais e "modus-operandi" das redes de firmas em condições de diversidade tecnológica. Rio de Janeiro, 1999. Tese de Doutorado em EconomiaInstituto de Economia, Universidade Federal do Rio de Janeiro.

— Sul: análise exploratória. In: Anais ANPEC/SUL, 2002.

CAMPOS, R. R.; NICOLAU, J. A.; BARBETTA, P. A. A. Aspectos metodológicos para pesquisa de micro e pequenas empresas em arranjos produtivos locais. Nota Técnica, n. 2 (do Programa de pesquisa sobre micro e pequenas empresas em arranjos produtivos locais no Brasil). Florianópolis: UFSC, 2002.

DOSI, G. The Nature of the Innovative Process. In: DOSI; FREEMAN; NELSON; SILVERBERG; SOETE. Technical Change and Economic Theory. Pinter Publishers, Londres. (cap.10), 1988.

EDQUIST, C. Systems of Innovation Approaches: their emergence and characteristics. In: EDQUIST, C. (Ed.). Systems of innovations: technologies, institutions and organizations. Chapter 1, Londres: Pinter, 1997.

FERRAZ, J. C.; KUPFER, D.; HAGUENAUER, L. Made in Brazil: desafios competitivos para a indústria. Rio de Janeiro. Campus., 386 p., 1996.

FRANSMAN Information, knowledge, vision and theories of the firm. In: Industrial and corporate change. Oxford University Press, v. 3, n. 3., 1994.

HIRATUKA, C. Estruturas de coordenação e relações interfirmas: uma interpretação a partir da teoria dos custos de transação e da teoria neo-schumpeteriana. Revista de Economia de Empresas, São Paulo, v. 4, n.1, p. 17-32, jan./mar. 1997.

LUNDVALL, B. A. et al (2001) National Systems of production, innovation and competencebuilding. Texto apresentado na Nelson and Winter DRUID Summer Conference. Denmark, June, 2001.

MALERBA, F. Learning by firms and incremental technical change. The Economic Journal, p. 845-859. July, 1992.

MALHOTRA, N. K. Pesquisa de marketing: uma orientação aplicada. 3. ed. Porto Alegre: Bookman, 2001.

PONDÉ, J. L. Estratégia de integração em uma abordagem dinâmica da firma. Anais do XX Encontro da ANPEC: São Paulo, 1992.

RAIS - Relação Anual de Informações Sociais. Ministério do Trabalho e Emprego, Bases Estatísticas. Brasília, 2003. 
STORPER, M.; HARRISON, B. Flexibility, hierarchy and regional developments the changing structure of industrial production system and their forms of governance in the 1990s. Research Policy, v. 20, n. 5, 1991.

SUZIGAN, W.; GARCIA, R.; FURTADO, J. Governança de sistemas produtivos locais de micro, pequenas e médias empresas. In: LASTRES, H. M. M.; CASSIOLATO, J. E.; MACIEL, M. L. (Orgs.). Pequena empresa: cooperação e desenvolvimento local. Rio de Janeiro: Relume Dumará: UFRJ, Instituto de Economia, p. 67-84, 2003.

TEECE, D. Technological Development and the Organization of Industry. Artigo apresentado no Seminaire International sur la Science, la Technologie et la Croissance Economique. Paris: OECD, maio, 1989.

VARGAS, M. Proximidade territorial, aprendizado e inovação: um estudo sobre a dimensão local de processos de capacitação inovativa em arranjos e sistemas produtivos no Brasil. Rio de Janeiro: UFRJ/IE (tese de doutourado), 2002.

YOGUEL, G. Entorno productivo y ventajas competitivas: el caso de uma trama siderúrgica. Argentina: Pilar, 2003. 